\title{
Aislamiento de serovariedades de Salmonella enterica a partir de heces de animales domésticos y silvestres en cautiverio
}

\section{Isolation of serovars of Salmonella enterica from feces of domestic and wild animals in captivity}

\author{
Pidone Claudio luis ${ }^{1 *}$, Zerpa Corina ${ }^{3}$, Caffer María Inés ${ }^{4}$, \\ Moroni Mirian Patricia ${ }^{4}$, Comba Eduardo Rubén ${ }^{2}$
}

1. Cátedra de Enfermedades Infecciosas. 2. Cátedra de Microbiología. Facultad de Ciencias Veterinarias, Universidad Nacional de Rosario. 3. Servicio Veterinario, Zoológico de Mendoza. 4. Servicio de Enterobacterias, Instituto Nacional de Enfermedades Infecciosas (INEI) - ANLIS. Dr. Carlos G. Malbrán. Argentina.

* Correo electrónico del autor de contacto: cpidone@fueter.unr.edu.ar

\begin{abstract}
Resumen
Se recolectaron muestras de materia fecal correspondientes a 27 especies de animales en cautiverio pertenecientes al Jardín Zoológico de Mendoza (Argentina), con el fin de encontrar portadores asintomáticos de Salmonella. Las muestras de materia fecal obtenidas con hisopos se sembraron en caldo tetrationato base de Müller-Kauffmann y se incubaron a $43{ }^{\circ} \mathrm{C}$ en baño María durante $24 \mathrm{~h}$. Alícuotas de este medio se sembraron en agar xilosa-lisina-desoxicolato y, finalmente, las colonias desarrolladas se identificaron utilizando pruebas bioquímicas convencionales. Como resultado, se aisló Salmonella serovar Meleagridis a partir de muestras de un oso polar y Salmonella serovar Give a partir de las de un oso pardo y un mono carayá. Ambas serovariedades están asociadas con casos de salmonelosis en humanos.
\end{abstract}

\section{Palabras clave}

Salmonella, zoológico, serovariedades, zoonosis

\begin{abstract}
Fecal samples corresponding to 27 species of animals in captivity in the Mendoza Zoo (Argentina) were collected, in order to find asymptomatic carriers of Salmonella. The fecal samples obtained with swabs were seeded in Müller-Kauffmann base tetrathionate and incubated at $43{ }^{\circ} \mathrm{C}$ in a water bath for $24 \mathrm{~h}$. Then, aliquots of this medium were seeded on xylose-lysine-deoxycholate agar and, finally, formed colonies were identified using conventional biochemical tests. As a result, Salmonella serovar Meleagridis was isolated from a polar bear and Salmonella serovar Give from a brown bear and a carayá monkey samples. Both serovars are associated with cases of salmonellosis in humans.
\end{abstract}

\section{Key words}

Salmonella, zoo, serovars, zoonoses

Fecha de recepción: 11/04/2018

Fecha de aprobación: 09/10/2018
ANALECTA VeT 2018; Julio-Diciembre; 38(2):18-21

Impresa ISSN 03655 14-8 Electrónica ISSN 1514-2590

doi.org/10.24215/15142590e028 


\section{Introducción}

La salmonelosis puede afectar a un sinnúmero de especies y es muy común en animales domésticos: aves de corral, cerdos, bovinos y equinos; es menos frecuente en caninos y felinos. Las personas y los animales contraen la enfermedad comúnmente al ingerir agua de bebida contaminada, alimentos de origen animal crudos y también por contacto directo con las heces de animales infectados. En humanos son frecuentes los casos de gastroenteritis provocados por distintas cepas de Salmonella, la mayor parte de las veces debido al consumo de alimentos contaminados. Es frecuente aislar esta bacteria a partir de distintos productos de origen animal (Eng et al., 2015). Muchos animales silvestres también pueden ser portadores de Salmonella y, por lo tanto, posibles fuente de infección para el hombre y otros animales. Las especies confinadas en zoológicos han sido objeto de estudios de esta índole, y a partir de ellos se han aislado salmonelas (Lima et al., 2012; Silva Hidalgo et al., 2010). El objetivo de este trabajo fue determinar la presencia de Salmonella en la materia fecal de animales domésticos y silvestres en cautiverio e identificar las serovariedades presentes.

\section{Materiales y métodos}

En el período comprendido entre octubre de 2014 y septiembre de 2016, y sobre la base de las normas de la Asociación Mundial de Zoos y Acuarios (2018), se recolectaron un total de 51 muestras correspondientes a 27 especies animales en cautiverio pertenecientes al Jardín Zoológico de Mendoza (Argentina). Las especies estudiadas se consignan en la Tabla 1. Los hisopos con la materia fecal se colocaron en medio de transporte de Stuart (Laboratorio Britania SA, CABA, Argentina), se conservaron a $4{ }^{\circ} \mathrm{C}$ y se procesaron dentro de las $24 \mathrm{~h}$. Cada una de las muestras obtenidas se sembró en tubos que contenían $10 \mathrm{ml}$ de caldo tetrationato base de Müller-Kauffmann (Laboratorio Britania SA, CABA, Argentina) y se incubaron a $43^{\circ} \mathrm{C}$ en baño María durante $24 \mathrm{~h}$. Posteriormente, con un ansa de siembra se tomó una alícuota de la superficie de cada uno de los tubos y se sembró en agar xilosa-lisina-desoxicolato (XLD - Biokar Diagnostics, Francia), incubándose durante 24$48 \mathrm{~h}$ a $37{ }^{\circ} \mathrm{C}$ (Manual Oxoid, 2006). Las colonias sospechosas (rojas con centro negro) se identificaron utilizando pruebas bioquímicas convencionales tales como: agar TSI, IMViC, ONPG y ureasa (Caffer et al., 2007). La confirmación y posterior serotipificación de la cepa de Salmonella aislada se realizó en el Servicio de Enterobacterias del Instituto Nacional de Enfermedades Infecciosas (INEI) - ANLIS Dr. Carlos G. Malbrán.

\section{Resultados}

Se logró el aislamiento de Salmonella a partir de las heces de tres animales. Las especies estudiadas y los resultados obtenidos se resumen en la Tabla 1.

Se aisló Salmonella a partir de un oso polar (Ursus maritimus). La bacteria aislada se identificó como Salmonella enterica serovar Meleagridis. Un año después de este resultado, y dentro del período de estudio, se tomó una segunda muestra a partir del mismo animal, la cual resultó negativa.

También se aisló Salmonella a partir de las heces de un oso pardo (Ursus arctos) y de un mono carayá (Alouatta caraya). Ambos aislamientos se identificaron como Salmonella serovariedad Give. Se repitió dos veces más la toma de muestras a partir de estos mismos animales dentro del período de estudio, siendo todos los resultados negativos.

\section{Discusión}

En el caso del oso polar, no manifestaba signos de enfermedad en el momento de la toma de la muestra que resultó positiva, pero se informó que en días previos había tenido diarrea. Esto, sin embargo, se creyó asociado con la dieta. La fuente de infección se desconoce y se cree que podría relacionarse con la alimentación; en este sentido, se determinó que el oso comía pescado, pollo, carne con hueso, corazón bovino, frutas y verduras. El pollo provenía de diferentes proveedores.

Las otras dos especies infectadas con la serovariedad Give no manifestaron ningún tipo de signos clínicos en el momento de la toma de las muestras. En un principio, se analizó la posibilidad de que ambos animales fueran portadores crónicos asintomáticos, pero los resultados obtenidos en los análisis posteriores fueron negativos. Sin poder descartar una infección crónica asintomática, se cree que una fuente de infección común desconocida pudo haber sido la causa de estas infecciones, quizá algún elemento de uso común, como los alimentos consumidos por ambos, o la contaminación del carro que transportó dichos alimentos. Los animales no eran convivientes, pero se hallaban en jaulas no muy distantes una de otra.

Salmonella Meleagridis ha sido aislada previamente de personas con diarrea (Zaidi et al., 2006) y Salmonella Give a partir de materia fecal de bovinos con diarrea (Higgins et al., 1997), de heces de una persona con síndrome diarreico (Noseda et al., 2002) y de un absceso esplénico de un paciente humano inmunocompetente, que posiblemente haya estado asociado con el consumo de carne picada cruda (Girardin et al., 2016). La presencia de estas serovariedades de carácter zoonótico implica un problema de salud pública, 
Tabla 1. Cantidad de muestras totales y positivas por especie animal

\begin{tabular}{lcc}
\hline Especie & $\begin{array}{c}\text { Cantidad de } \\
\text { muestras }\end{array}$ & $\begin{array}{c}\text { Muestras } \\
\text { positivas }\end{array}$ \\
\hline Águila coronada (Harpyhaliaetus & 1 & - \\
coronatus) & 2 & - \\
Búfalo de la India (Bubalus bubalis) & 1 & - \\
Cabra de Juan Fernández (Capra aegagrus) & 2 & - \\
Camello bactriano (Camelus bactrianus) & 1 & - \\
Cebra (Equus quagga) & 1 & - \\
Chimpancé (Pan troglodytes) & 1 & - \\
Elefante africano (Loxodonta africana) & 2 & - \\
Elefante asiático (Elephas maximus) & 3 & - \\
Gamo (Dama dama) & 2 & - \\
Ganso (Anser anser) & 3 & - \\
Hipopótamo (Hippopotamus amphibius) & 1 & - \\
Llama (Lama glama) & 1 & - \\
Mara (Dolichotis patagonum) & 5 & (S. Give) \\
Mono carayá (Alouatta caraya) & 2 & - \\
Nandú (Rhea americana) & 6 & 1 (S. Give) \\
Oso pardo (Ursus arctos) & 2 & - \\
Oso polar (Ursus maritimus) & 1 & - \\
Oveja somalí (Ovis aries steatopigas) & 1 & - \\
Papión sagrado (Papio hamadryas) & 1 & - \\
Pavo real (Pavo cristatus) & 1 & - \\
Pecarí de collar (Pecari tajacu) & 1 & - \\
Pichi (Zaedyus pichiy) & 2 & - \\
Poni (Equus ferus caballus) & 3 & - \\
Puma (Puma concolor) & 1 & - \\
Tejú/lagarto overo (Tupinambis teguixin) & 3 & - \\
Tortuga terrestre argentina (Chelonoidis & 1 & - \\
chilensis) & & - \\
Zorro gris patagónico (Lycalopex griseus) & - & - \\
& & - \\
\hline
\end{tabular}

siendo un riesgo para personas y animales, en especial para el personal que trabaja en jardines zoológicos y que está en contacto con los animales. Además, fortalece la importancia de controlar potenciales reservorios de éste y quizá de otros agentes infecciosos zoonóticos en este tipo de parques.

\section{Conclusiones}

En este trabajo se aisló Salmonella serovar Meleagridis a partir de un oso polar y Salmonella serovar Give a partir de un oso pardo y de un mono carayá, portadores asintomáticos confinados en un parque zoológico, con las implicancias epidemiológicas que esto pudiera llegar a tener.

\section{Conflicto de intereses}

Todos los autores declaran que no existe conflicto de intereses.

\section{Bibliografía}

Asociación Mundial de Zoos y Acuarios: código de ética y bienestar animal. Disponible en: http:// www.waza.org/files/webcontent/1.public_site/ 5.conservation/animal_welfare/ waza\%20code\%20of\%20ethics\%20sp.pdf (consultado 06/05/2018).

Caffer MI, Terragno, R. 2001. Manual de procedimientos para la caracterización de Salmonella. Disponible en: https://docplayer.es/ 12601568-Manual-de-procedimientos-para-lacaracterizacion-de-salmonella.html (consultado 05/04/ 2018)

Eng SK, Pusparajah P, Ab Mutalib NS, Ser HL, Chan KG \& Lee LH. 2015. Salmonella: A review on pathogenesis, epidemiology and antibiotic resistance. Frontiers in Life Science. 8(3):284-93. doi: 10.1080/21553769.2015.1051243

Girardin F, Mezger N, Hächler H, Bovier PA. 2006. Salmonella serovar Give: An unusual 
pathogen causing splenic abscess. European Journal of Clinical Microbiology Infectious Diseases. 25:272-4.

doi: 10.1007/s10096-006-0122-2

Higgins R, Desilets A, Cantin M, Messier S, Khakhria R, Ismail J, Mulvey MR, Daignault D, Caron H. 1997. Outbreak of Salmonella Give in the province of Quebec. Canadian Veterinary Journal. 38:780-1.

Lima DCV, Siqueira DB, Mota RA, Rameh-deAlbuquerque LC, Souza SD, Santos AS, Silva LBG. 2012. Microbiologia de swabs retais e otológicos em carnívoros silvestres do zoológico do Parque Estadual de Dois Irmãos, Pernambuco. Pesquisa Veterinária Brasileira. 32(2):159-64.

Manual Oxoid. 2006. 9th Edition. Basingstoke (Inglaterra), Oxoid Limited.

Noseda RP, Bigalli MC, Andrich MG, Cordeviola JM. Bardón JC, Martínez AH, Combessies GM.
2002. Aislamiento de Salmonella en muestras clínicas humanas, animales y alimentos, durante 1988-2001. Veterinaria Argentina. 19:752-9.

Silva-Hidalgo G, López-Moreno HS, OrtizNavarrete VF, Alpuche-Aranda C, RendónMaldonado JG, López-Valenzuela JA, LópezValenzuela M, Juárez-Barranco F. 2013. Prevalence of Salmonella enterica serovar Albany in captive zoo wild animals in the Culiacán Zoo in Mexico. Journal of Zoo and Wildlife Medicine. 44(1):8-14. doi: 10.1638/1042-7260-44.1.8

Zaidi MB, McDermott PF, Fedorka-Cray P, Leon V, Canche C, Hubert SK, Abbott J, León Zhao S, Headrick M, Tollefson L. 2006. Nontyphoidal Salmonella from human clinical cases, asymptomatic children, and raw retail meats in Yucatan, México. Clinical infectious diseases. 1: 42(1):21-8. doi: 10.1086/498508 